\title{
Pol-tako — the first nationwide Polish multicenter analysis of patients with takotsubo syndrome
}

\author{
Monika Budnik', Radosław Piątkowski', Martyna Zaleska', Dorota Ochijewicz', Małgorzata Zalewska-Adamiec²,

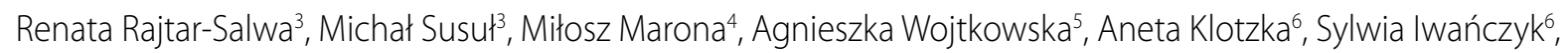 \\ Dominika Duda-Pyszny', Jacek Legutko ${ }^{8}$, Mariusz Gąsior ${ }^{7}$, Maciej Lesiak ${ }^{6}$, Jarosław Kaźmierczak' ${ }^{9}$ Andrzej \\ Wysokiński ${ }^{5}$, Piotr Ponikowski10, Przemysław Leszek ${ }^{11}$, Stanisław Bartuśs ${ }^{3}$, Sławomir Dobrzycki², Grzegorz Opolski
}

${ }^{1} 1^{\text {st }}$ Chair and Department of Cardiology, Medical University of Warsaw, Warszawa, Poland

2Department of Invasive Cardiology, Medical University of Bialystok, Białystok, Poland

${ }^{3}$ Department of Cardiology and Cardiovascular Interventions, University Hospital, Kraków, Poland

${ }^{4}$ Department of Intensive Cardiac Care, The National Institute of Cardiology, Warszawa, Poland

${ }^{5}$ Department of Cardiology, Medical University of Lublin, Lublin, Poland

${ }^{6} 1^{\text {st }}$ Department of Cardiology, Poznan University of Medical Sciences, Poznań, Poland

7Department of Cardiology, SMDZ in Zabrze, Medical University in Katowice, Silesian Center for Heart Diseases, Zabrze, Poland

${ }^{8}$ Jagiellonian University Medical College, Faculty of Medicine, Institute of Cardiology, Department of Interventional Cardiology, John Paul II Hospital, Kraków, Poland

${ }^{9}$ Department of Cardiology, Pomeranian Medical University, Szczecin, Poland

${ }^{10}$ Department of Heart Diseases, Wroclaw Medical University, Wrocław, Poland

"Department of Heart Failure and Transplantology, The National Institute of Cardiology, Warszawa, Poland

\author{
Correspondence to: \\ Monika Budnik, MD, PhD \\ $1^{\text {st }}$ Chair and Department of \\ Cardiology, \\ Medical University of \\ Warsaw, \\ Banacha 1a, 02-097 \\ Warszawa, Poland, \\ phone: +48 225991958 \\ e-mail: \\ moni.budnik@gmail.com \\ Copyright by the Author(s), \\ 2021 \\ Kardiol Pol. 2021: \\ 79 (7-8): 867-869. \\ DOl: 10.33963/KP.a2021.0037 \\ Received: \\ April 23, 2021 \\ Revision accepted: \\ June 13, 2021 \\ Published online: \\ June 14, 2021
}

\section{INTRODUCTION}

Takotsubo syndrome (TTS) was initially described by Hikaru Sato in Japan in 1990 [1]. The first case involving the Polish population was published in Kardiol Pol (The Polish Heart Journal) in 2006 [2].

One of the largest TTS registries in the world, the Inter-TAK registry, is coordinated by researchers from the University Heart Center at the University Hospital in Zurich [3]. Takotsubo syndrome is diagnosed in $1 \%-3 \%$ of patients with suspicion of myocardial infarction [4]. Its pathophysiology is currently not fully understood, but the association with stress is apparent [5]. Acute stress, either emotional or physical, is a factor preceding about $50 \%$ of all episodes of TTS. Chronic stress, (e.g., depression, neoplastic disease) increases the risk of a TTS episode.

During the 2019 SARS-CoV-2 pandemic, unprecedented social distancing measures were introduced. This resulted in a sudden and significant reduction in social interaction by encouraging people to stay at home, closing schools and recreation facilities, and introducing work at home as commonplace. This represented a strong stress factor.

\section{AIMS}

The aim of this study is to describe and discuss population characteristics of Polish patients hospitalized due to TTS and clinical presentation and prognosis of patients with TTS before and during the COVID-19 pandemic.

\section{METHODS}

The data (Pol-tako, ClinicalTrials.gov identifier, NC 04634487) will be collected both retrospectively and prospectively. Its retrospective arm will include ten Polish cardiology centers experienced in treating TTS. The prospective arm will include cardiology centers which have around-the-clock catheterization laboratories and dedicated COVID-19 centers. Patients concurrently hospitalized with TTS and COVID-19 will be included in the analysis.

We have estimated that each center will include between fifty and three hundred patients. Consequently, we anticipate that we will gather a total number of 2000 cases.

The anonymized database will include demographic and clinical characteristics, the treatment used, laboratory investigations, electrocardiograms, echocardiography, coronary imaging, and short-term in-hospital prognosis (Table 1). 
Table 1. Data collected in the Pol-tako registry

\begin{tabular}{ll}
\hline Baseline characteristic & Demographic parameters \\
& Symptoms at admission \\
& Stress factor \\
& Comorbidities \\
& Risk factors \\
& Blood tests \\
& Electrocardiogram \\
& Echocardiography \\
& Angiography/computed tomo- \\
& graphy \\
& Electrocardiogram \\
$3^{\text {rd }}$ day & Echocardiography \\
& Electrocardiogram \\
$5^{\text {th }}$ day & Echocardiography \\
& \\
Clinical course & \\
Complications & \\
\hline
\end{tabular}

Based on the collected information, we will evaluate the clinical characteristics of patients with TTS and their prognosis among the Polish population. We will prepare a comparison of individuals hospitalized before and during the COVID-19 pandemic and will compare patients with and without coexisting SARS-CoV-2 infection.

The Ethics Committee of the Medical University of Warsaw granted approval to conduct this study. Due to the collection of data performed in a completely anonymous manner, there is no need to obtain consent for the study. Patients will not undergo any additional intervention and will be treated according to current recommendations.

The registry received patronage from the Association of Heart Failure and Association of Cardiovascular Intervention of the Polish Society of Cardiology.

\section{Statistical analysis}

Normally distributed continuous variables will be presented as mean values and standard deviations. Ordinal variables and non-normally distributed continuous variables will be presented as median values and interquartile ranges (IQR). Categorical data will be presented as the number of patients and percentages. The Fisher's exact test and the Mann-Whitney $U$ test will be used for categorical and continuous variables respectively. To determine the risk factors of endpoint (cardiogenic shock and death) occurrence, univariate and multivariate logistic regression will be applied. The factors that will be included in the univariate analysis will be demographic parameters, comorbidities, laboratory parameters, electrocardiogram, echocardiographic parameters, and clinical course.

$P$-value less than 0.05 will be considered significant. All tests are two-tailed. All statistical analyses will be performed using SAS software version 9.4 (SAS Institute Inc. Cary, NC, USA).

\section{RESULTS AND DISCUSSION}

Multiple criteria for TTS diagnosis, based on registries and observational studies, have been published. These were proposed, among others, by researchers from Mayo Clinic, the Japanese Research Committee for Idiopathic Cardiomyopathy, The Johns Hopkins Hospital, the Heart Failure Association of the European Society of Cardiology, and scientists from the InterTAK registry [5-9]. Polish patients were included only in the InterTAK registry but constituted less than $10 \%$ of the study population.

To date, interesting results have been published involving single-center experience regarding markers used in TTS diagnosis, sex differences, application of the GRACE scale, and poor prognosis of patients with chronic kidney disease or low body mass index (BMI) [10-14]. It would, however, be extremely valuable to verify these results for a large-scale population.

According to early global reports, the incidence of TTS has been significantly higher in patients admitted with acute coronary syndrome symptoms during the COVID-19 pandemic compared to the pre-pandemic era. Social isolation can account for multiple psychological disturbances, including stress, anxiety, depression, insomnia, anger, frustration, irritability, and boredom. These could have long-lasting consequences even after the end of lock-down or quarantine. The occurrence or intensification of emotional stress may be related to uncertainty and concerns about the future, compounded by systematic and alarming news (daily reports of infections and deaths). The increase in TTS incidence during COVID-19 may be linked to concerns over the viral infection and its consequences but also to psychological, social, and economic factors that have been part of the reaction to the pandemic. There have been a few published cases of TTS with coexisting COVID-19; however, the mechanism of myocardial injury in these patients is still unknown.

The proposed mechanism of COVID-19-induced cardiac injury is the destruction of ACE2 receptors, the surge in catecholamines due to the acute viral illness, severe hypoxia, and the associated acute respiratory distress syndrome observed in moderate-to-severe COVID-19 or cytokine storm [15].

We hope that the Pol-tako may be a valuable source of knowledge in this area.

\section{Article information}

Conflict of interest: None declared.

Open access: This article is available in open access under Creative Common Attribution-Non-Commercial-No Derivatives 4.0 International (CC BY-NC-ND 4.0) license, allowing to download articles and share them with others as long as they credit the authors and the publisher, but without permission to change them in any way or use them commercially. For commercial use, please contact the journal office at kardiologiapolska@ptkardio.pl. 
How to cite: Budnik M, Piątkowski R, Zaleska M, et al. Pol-tako - the first nationwide Polish multicenter analysis of patients with takotsubo syndrome. Kardiol Pol. 2021; 79(7-8): 867-869, doi: 10.33963/KP.a2021.0037.

\section{REFERENCES}

1. Sato $\mathrm{H}$, Tateishi $\mathrm{H}$, Uchida T. Tako-tsubo-like left ventricular dysfunction due to multivessel coronary spasm. In: Kodama K, Haze K, Hori M. ed. Clinical aspect of myocardial injury: from ischemia to heart failure. Kagakuhyoronsha Publishing Co, Tokyo 1990: 56-64

2. Grabowski M, Karpiński G, Kochman J, et al. Apical ballooning syndrome in a 57-year-old woman during premedication for general anaesthesia [Polish]. Kardiol Pol. 2006; 64(10): 1110-1112, indexed in Pubmed: 17089243.

3. Ghadri JR, Kato K, Cammann VL, et al. Long-term prognosis of patients with takotsubo syndrome. J Am Coll Cardiol. 2018; 72(8): 874-882, doi: 10.1016/j.jacc.2018.06.016, indexed in Pubmed: 30115226.

4. Prasad A, Dangas $G$, Srinivasan $M$, et al. Incidence and angiographic characteristics of patients with apical ballooning syndrome (takotsubo/stress cardiomyopathy) in the HORIZONS-AMI trial: an analysis from a multicenter, international study of ST-elevation myocardial infarction. Catheter Cardiovasc Interv. 2014; 83(3):343-348, doi: 10.1002/ccd.23441, indexed in Pubmed: 22121008.

5. Ghadri JR, Wittstein IS, Prasad A, et al. International expert consensus document on takotsubo syndrome (part I): clinical characteristics, diagnostic criteria, and pathophysiology. Eur Heart J. 2018; 39(22): 2032-2046, doi: 10.1093/eurheartj/ehy076, indexed in Pubmed: 29850871.

6. Prasad A, Lerman A, Rihal CS. Apical ballooning syndrome (Tako-Tsubo or stress cardiomyopathy): a mimic of acute myocardial infarction. Am Heart J. 2008; 155(3): 408-417, doi: 10.1016/j.ahj.2007.11.008, indexed in Pubmed: 18294473.

7. Kawai S, Kitabatake A, Tomoike H, et al. Takotsubo Cardiomyopathy Group. Guidelines for diagnosis of takotsubo (ampulla) cardiomyopathy.
Circ J. 2007; 71(6): 990-992, doi: 10.1253/circj.71.990, indexed in Pubmed: 17527002.

8. Wittstein IS. Stress cardiomyopathy: a syndrome of catecholamine-mediated myocardial stunning? Cell Mol Neurobiol. 2012; 32(5): 847-857, doi: 10.1007/s10571-012-9804-8, indexed in Pubmed: 22297544.

9. Lyon AR, Bossone E, Schneider B, et al. Current state of knowledge on Takotsubo syndrome: a Position Statement from the Taskforce on Takotsubo Syndrome of the Heart Failure Association of the European Society of Cardiology. Eur J Heart Fail. 2016; 18(1): 8-27, doi: 10.1002/ejhf.424, indexed in Pubmed: 26548803.

10. Budnik M, Kochanowski J, Piatkowski R, et al. Simple markers can distinguish takotsubo cardiomyopathy from ST segment elevation myocardial infarction. Int J Cardiol. 2016; 219: 417-420, doi: 10.1016/j. ijcard.2016.06.015, indexed in Pubmed: 27367474.

11. Budnik M, Nowak R, Fijałkowski $M$, et al. Sex-dependent differences in clinical characteristics and in-hospital outcomes in patients with takotsubo syndrome. Pol Arch Intern Med. 2020; 130(1): 25-30, doi: 10.20452/pamw.14970, indexed in Pubmed: 31517898.

12. Zalewska-Adamiec M, Kuzma L, Dobrzycki S, et al. The GRACE scale in the prognosis of patients with takotsubo syndrome. J Interv Cardiol. 2020; 2020: 4340930, doi: 10.1155/2020/4340930, indexed in Pubmed: 32405274.

13. Zalewska-Adamiec M, Małyszko J, Bachórzewska-Gajewska H, et al. Takotsubo syndrome and chronic kidney disease: a deadly duet in long-term follow-up. Pol Arch Intern Med. 2018; 128(9): 518-523, doi: 10.20452/pamw.4309, indexed in Pubmed: 30057376.

14. Zalewska-Adamiec M, Malyszko J, Bachórzewska-Gajewska $\mathrm{H}$, et al. Takotsubo syndrome - fatal prognosis of patients with low body mass index in 5-year follow-up. Arch Med Sci. 2019; 16(2): 282-288, doi: 10.5114/aoms.2019.87082, indexed in Pubmed: 32190137.

15. Almas T, Khedro T, Haadi A, et al. COVID-19-induced takotsubo cardiomyopathy: venturing beyond the obvious. Ann Med Surg (Lond). 2021; 65: 102291, doi: 10.1016/j.amsu.2021.102291, indexed in Pubmed: 33981423. 